NBER WORKING PAPER SERIES

\title{
PHYSICAL CAPITAL, KNOWLEDGE CAPITAL AND THE CHOICE BETWEEN FDI AND OUTSOURCING
}

\author{
Yongmin Chen \\ Ignatius J. Horstmann \\ James R. Markusen \\ Working Paper 14515 \\ http://www.nber.org/papers/w14515
}

\author{
NATIONAL BUREAU OF ECONOMIC RESEARCH \\ 1050 Massachusetts Avenue \\ Cambridge, MA 02138 \\ December 2008
}

The authors thank the participants and discussants at a number of seminars and conferences for helpful comments and suggestions. Presentations were at the NBER ITO Working Group Meeting in Cambridge, the ERWIT conference in Appenzell, Switzerland, the ETSG conference in Warsaw, and the Norface conference in Munich, all held in 2008. The views expressed herein are those of the author(s) and do not necessarily reflect the views of the National Bureau of Economic Research.

NBER working papers are circulated for discussion and comment purposes. They have not been peerreviewed or been subject to the review by the NBER Board of Directors that accompanies official NBER publications.

(C) 2008 by Yongmin Chen, Ignatius J. Horstmann, and James R. Markusen. All rights reserved. Short sections of text, not to exceed two paragraphs, may be quoted without explicit permission provided that full credit, including $(\mathrm{C}$ notice, is given to the source. 
Physical Capital, Knowledge Capital and the Choice Between FDI and Outsourcing

Yongmin Chen, Ignatius J. Horstmann, and James R. Markusen

NBER Working Paper No. 14515

December 2008

JEL No. F2,F23,L2,L22,L24

\section{ABSTRACT}

There exist two approaches in the literature concerning the multinational firm's mode choice for foreign production between an owned subsidiary and a licensing contract. One approach considers environments where the firm is transferring primarily knowledge-based assets. An important assumption there is that the relevant knowledge is absorbed by the local manager or licensee over the course of time: knowledge is non-excludable. More recently, a number of influential papers have adopted a property-right view of the firm, assuming the application abroad of physical capital, the owner of which retains full and exclusive rights to the capital should a relationship break down. In this paper we combine both forms of capital assets in a single model. The model predicts that foreign direct investment (owned subsidiaries) is more likely than licensing when the ratio of knowledge capital to physical capital is high, or when market value is high relative to the book value of capital (high Tobin's-Q).

Yongmin Chen

Department of Economics

University of Colorado

Boulder, CO 80309

Yongmin.chen@colorado.edu

Ignatius J. Horstmann

University of Toronto

Rotman School of Management

105 St. George St.

Toronto, ON M5S 3E6

Canada

ihorstmann@rotman.utoronto.ca
James R. Markusen

Department of Economics

University of Colorado

Boulder, CO 80309-0256

and NBER

james.markusen@colorado.edu 


\section{INTRODUCTION}

Foreign direct investment (FDI) has grown at rates greatly outpacing the growth in world trade over the last several decades. This has naturally led to increased interest in FDI by academic researchers and policy makers. Part of that interest has been directed to the determinants of the choice of mode by which firms service foreign markets, including options such as exporting, owned foreign affiliates (FDI), licensing and subcontracting, and joint ventures. This in turn relates to more general discussion in microeconomics about the "boundaries of the firm": decisions as to which activities should be undertaken within the ownership structure of the firm, and which activities should be contracted or outsourced to arm's-length firms.

There is a rich and extensive literature on the boundaries of the firm, and we can make no attempt to survey it here. Instead, we will direct our efforts along lines which have been productive in the field of international trade, where researchers have attempted to model a multinational's decision as to whether to establish a foreign subsidiary or contract with a foreign supplier to produce a good for local sales or for export back to the parent firm. These questions used to be referred to as the "internalization" problem, but more recently are being referred to by the converse label, "outsourcing". But they are really the same thing: whether or not to internalize an activity inside the firm, or to outsource it to an arm's-length firm.

Much of the more recent literature under the name outsourcing has drawn from an approach which, we assert, focuses on properties of physical capital such as plant and equipment. On the other hand, the empirical literature and other recent theoretical literature has emphasized the importance of knowledge-based assets in ex-

plaining the decision to become a multinational firm. An earlier theoretical literature 
under the internalization label also took the latter approach.

The purpose of this paper is to inquire whether or not the nature of the capital required by a subsidiary makes an important difference to the choice of mode, either subsidiary or licensee. Specifically, we wish to differentiate between physical capital and knowledge-based capital assets, and ask whether a more physical capital-intensive firm will be more or less likely to chose internalization via a subsidiary rather than outsource compared to a knowledge-capital-intensive firm.

As just alluded to, the somewhat older literature assumed knowledge-based assets and in particular assumed that the multinational firm (the principal) cannot prevent a licensee (the agent) from absorbing or learning the relevant knowledge over time. Even though the multinational "owns" the knowledge-based asset, it gets transferred to a licensee. This literature emphasizes the jointness property of knowledge capital, the ability to use it fully in multiple locations at the same time (Markusen's (2002) knowledge-capital model), which leads to multi-plant production in the first place. It suggests that the jointness properly also leads to the problem of asset dissipation: knowledge-assets are easily transferred but also easily absorbed by the licensee. Formal models include Horstmann and Markusen (1987), Ethier and Markusen (1996), Markusen (2001), Fosfuri, Motta and Rønde (2001) and Glass and Saggi (2002).

By contrast, more recent literature is focused around the Grossman-HartMoore property-right approach (Grossman and Hart (1986) and Hart and Moore (1990)), which seems (implicitly) more appropriate for physical capital in that the relevant asset has no jointness property and that the owner of the residual rights has full control of the asset if a relationship or negotiation breaks down. Important papers 
include Grossman and Helpman (2002, 2004), Antrás (2003, 2005), and Feenstra and Hanson (2005).

Our model combines the two approaches in a simple two-period incompletecontracting model. A firm requires both physical and knowledge capital for a foreign subsidiary, along with non-contractible effort by a foreign licensee or manager. Effort is relatively more important as a complement to physical capital than knowledge capital, creating the well-understood advantage for using a licensee who owns the physical capital and thus captures the full benefit of his or her effort. However, knowledge capital transferred by the multinational is absorbed by the licensee during the first period regardless of who "owns" it. We assume that the value of this knowledge to a manager or licensee outside the relationship depends on working with the physical capital, the two assets being complements. Thus the advantage to the multinational in owning the physical capital is that it reduces the incentives or ability of the licensee to use the knowledge for private or outside uses in period 2.

This tension, ownership by the multinational reduces agent's effort while preserving the value of the knowledge capital, is the fundamental difference between the present paper and previous ones. Our result is that firms that are more physicalcapital intensive will tend to license (outsource), while firms that are more knowledgecapital intensive will tend to establish subsidiaries (internalize). We believe that this is consistent with all available empirical evidence.

We are of course aware that some existing literature emphasizes that capitalintensive firms are more like to establish subsidiaries (Antrás 2003), but this refers to capital use relative to labor and materials, not to physical versus knowledge-capital intensity. Our model does not offer cross-section predictions about mode choice as 
a function of industry or firm capital-labor ratios. Rather, our predictions would more appropriately be examined by using a type of Tobin's $q$; specifically, the ratio of a firm's market value (reflecting knowledge-based assets as well as physical capital) to its book value of capital (largely reflecting physical capital only). Our prediction would be that firms/industries with higher $q$ 's would be more likely to establish foreign subsidiaries. Existing evidence, reviewed in Markusen (1995, 2002) and Caves (2007) does indeed suggest that this is the case. ${ }^{1}$ Another implication of our theory is that when there is stronger protection for knowledge capital, the incentive for licensing tends to be higher relative to the incentive for FDI. ${ }^{2}$

\section{THE MODEL}

A multinational firm (MNE) in the North, denoted as $M$, plans to produce a product (either intermediate or final) in the South due to cost advantages of manufacturing there. There are two periods of production, $t=1,2$, and there is no discounting. Production in the South requires the services of a local agent/manager, denoted as $A$, and two types of asset services: physical capital and knowledge capital or intellectual property. There is an exogenous and fixed amount of physical capital, $K$, that can

\footnotetext{
${ }^{1}$ See Morck and Yeung $(1991,1992)$ for evidence on the importance of information-related intangible assets in the FDI decision. For events in which firms do transfer technology abroad, articles by Davidson and McFetridge (1984), Mansfield and Romeo (1980), Teece (1986), and Wilson (1977) show technology is more likely to be transferred internally within the firm by $R \& D$ intensive firms producing new and technically complex products.

${ }^{2}$ Smith (2001) finds that stronger foreign patent rights increase US firms transfers of knowledge more by licensing than by affiliate sales. Yang and Maskus (2001) find that countries with stronger patent rights attract larger arm's-length volumes of licensed technology, although licensing is not compared to FDI. Maskus, Saggi and Puttitanum (2005) find that stronger patent protection increases the probability of inward FDI and has very little effect on licensing; but they note that this overall finding is driven by high technology sectors, and that lower technology sectors have the opposite result (stronger protection increases licensing more than FDI).
} 
only be acquired in the beginning of $t=1$ and that is required for production in both periods. Either $M$ or $A$ can own the physical capital $K$; whereas only $M$ initially owns the knowledge capital, with a fixed and exogenous amount equal to $S$.

At the beginning of $t=1, M$ makes a once-for-all choice between two possible organizational forms: foreign direct investment (FDI) or outsourcing. With FDI, $M$ acquires (and owns) the physical capital used for production in the South and employs $A$ under a sequence of one-period employment contract to manage a production process utilizing $M$ 's capital. A's hiring occurs at the beginning of $t=1$ and $A$ 's employment contract is re-negotiated at the beginning of $t=2$. $M$ also decides each period how much knowledge capital to transfer to $A$ to be utilized in production.

With outsourcing, $A$ acquires (and owns) the physical capital, with capital acquisition again occurring at the beginning of $t=1 . M$ signs a one-period licensing contract with $A$ that licenses an amount $s_{1}$ of $M$ 's knowledge capital to $A$ for use in production at $t=1$. This licensing agreement is re-negotiated at the beginning of $t=2$, with an amount $s_{2}$ transferred at $t=2$.

The cost of physical capital is $r K$. As in Grossman and Hart (1989), ownership of physical capital bestows control rights on the owner. Specifically, the owner can decide the uses to which the capital can be put and can exclude access to the capital for any other uses at any time. That having been said, effort from the agent is often required to improve or maintain the efficiency (usefulness) of the physical capital. We shall make these points clear shortly when we specify the payoff functions of the players.

Knowledge (or intellectual ) capital, by contrast, does not have the same excludability properties. The owner of knowledge capital may not be able to control to the 
same extent the uses to which the capital is put and to capture the returns that the Knowledge capital generates. In essence, property rights to Knowledge capital are harder to define and protect than is the case for physical capital. We capture these features of Knowledge capital in the following way. We assume that, at $t=1$, there exists a fraction $\sigma<1$ of $S$ that is "explicit knowledge" in the sense that the uses of this part of $M$ 's Knowledge capital can be defined in a $t=1$ licensing agreement, they can be measured and the returns appropriated by $M$. In this sense, the fraction $\sigma$ of $M$ 's Knowledge capital can be "owned" in the same way as physical capital is owned. A fraction $1-\sigma$ of $S$ is "tacit knowledge" and is not contractible at $t=1$ in the sense that its current and future uses cannot be controlled by $M$ in a $t=1$ licensing agreement and any returns that it generates cannot be specifically appropriated by $M$ in the agreement. The value of $\sigma$ is assumed to be exogenous to the firm and can be thought of as capturing either characteristics of the Knowledge capital utilized by $M$ or a characteristic of the legal regime of the country in which $M$ is contracting. For simplicity, we assume that all Knowledge capital is contractible at $t=2 .^{3}$

Note that this set of assumptions allows a simple characterization of the environment in which $M$ and $A$ operate. Specifically, the values of $K, S$ and $\sigma$ completely define the environment - characteristics of the relevant industry/product - under consideration. The values of $K$ and $S$ give the physical relative to knowledge capital intensity of the industry while $\sigma$ gives features of the appropriabilty of $M$ 's knowledge asset. Subsequent analysis will consider how variation in the economic environment - variation in $(K, S, \sigma)$ - affects the observed pattern of outsourcing and FDI.

For any given $K$ and knowledge asset $s_{i}$ for $i=1,2$, the maximum gross surpluses

\footnotetext{
${ }^{3}$ As it shall be clear later, $M$ does benefit from withholding $S$ in the equilibrium of $t=2$, and hence our results are still valid without this assumption.
} 
that accrue to $M$ and $A$ from utilizing $K$ and $s_{i}$ at $t=1$ and at $t=2$ are $U_{1}\left(K, s_{1}\right)$ and $U_{2}\left(K, s_{2}\right)+V(e \mid K)$, respectively, where $U_{i}(K, 0) \geq 0$, e is $A^{\prime} s$ effort during $t=1$ that affects the return in $t=2$, and $V(e \mid K)$ is a concave function of $e$ for any given value of $K .{ }^{4}$ We allow the possibility that $U_{i}(K, 0)>0$, in which case agent $A$ can have alternative uses for $K$ even if $s_{i}=0$. That is, we allow the possibility that $K$ can either be used for producing $M^{\prime} s$ product or for some alternative purpose benefiting $A$ (e.g., $K$ can be used for $A^{\prime} s$ private benefits). We assume that producing $M^{\prime} s$ product always yields higher payoffs than any alternative use when $s_{i} \geq \sigma S$, but the alternative payoff could be higher if $s<\sigma S$.

There is a perfectly elastic supply of agents with opportunity cost $W \geq 0$ in each period. However, the agent not owning capital at $t=1$ ( $M$ in the case of outsourcing and $A$ in the case of FDI) is not able to raise the amount $K$ sufficiently quickly to be able to produce alone at $t=2$. This fact produces a (potential) specific relationship between $M$ and $A$ at $t=2 \cdot{ }^{5}$ In this case, the $t=2$ surplus is allocated based on the Nash bargaining solution. Both $A$ and $M$ are risk neutral and make choices to maximize expected income.

We also assume that, at $t=1, M$ has access to perfect capital markets while $A$ has only limited ability to borrow against future income. Specifically, under outsourcing $A$ is only able to cover a fraction $\gamma \in(0,1]$ of $t=1$ costs via the capital markets. The remainder must be covered out of $t=1$ revenues. As will be seen later, this inability on $A$ 's part to borrow against future income limits $M$ 's ability to extract $t=2$ surplus from $A$ via the initial licensing agreement. It also forces $M$ to bear

\footnotetext{
${ }^{4}$ We emphsize that $K$ is a fixed parameter for our model, and we include it in the payoff functions so that we can see the effects of this parameter; on the other hand, both $s_{1}$ and $s_{2}$ are choice varialbes.

${ }^{5}$ This is relevant in the case of oursourcing, where the agent, who owns $K$, can demand the sharing of returns from using $S$ in $t=2$.
} 
some of the costs of $A$ 's capital investment.

Throughout our analysis, we shall maintain:

Assumption 1. (i) $U_{i}\left(K, s_{i}\right)$ increases in both $K$ and $s_{i}$ for all $s_{i} \leq S$. (ii) $V(e \mid K)$ increases in $e$. (iii) $U_{2}(K, 0)+V(0 \mid K) \geq(1+\gamma) W$. (iv) $V(0 \mid K) \leq W$.

Part (i) of Assumption 1 is quite natural and simply states that returns are higher with a higher amount of $K$ or $S$. Part (ii) says that $A^{\prime} s$ effort during $t=1$ would improve (maintain) the efficiency of physical capital $K$. Part (iii) ensures that $A^{\prime} s$ payoff in $t=2$ from production is high enough relative to its opportunity cost (i.e., (iii) will be required as a sort of participation constraint). (iv) says that there cannot be too much improvement in the value of physical asset if $A$ exerts no effort during $t=1$.

Notice that we allow $V(e \mid K)$ to be either positive or negative. ${ }^{6}$ For instance, $V(e \mid K)$ could be the depreciation (repair) cost of $K$ in $t=2$, as, for example, $V(e \mid K)=-\delta r K(1-e)^{2}<0$, and $e$ simply reduces this cost. Or $e$ could be $A^{\prime} s$ effort to find additional use for $K$ that adds value in $t=2$. For instance, a by-product may be produced with $K$, in addition to the product already being produced using $K$, in which case $V(e \mid K)>0 .{ }^{7}$ We shall later present examples where Assumption 1 is satisfied.

To summarize, the timing of the game is as follows:

At the beginning of $t=1, M$ chooses between FDI and outsourcing. If $M$ chooses

\footnotetext{
${ }^{6}$ However, if $V(e \mid K)<0, U_{2}(K, 0)$ will need to be high enough to satisfy (iii).

${ }^{7}$ This positive $V$ is to be distinguished from $A^{\prime} s$ using $K$ for private benefits that reduce the return of $K$ to $M$. For convenience and to capture the idea that effort is more important to improve or maintain the usefulness of physical capital, we assume $V$ does not depend on $s$. This is certainly the case, for instance, if $V$ represents the depreciation of $K$. This assumption is not essential for the main insights of our analysis.
} 
FDI, then $M$ offers $A$ an employment contract involving payment to $A$ of $w_{1}$; if $M$ chooses outsourcing, $M$ and $A$ negotiate a contract involving a transfer to $A$ of knowledge capital, $s_{1}$, and a licensing payment from $A$ to $M$ of $l_{1}$. In either case, should $A$ accept the contract, $A$ chooses an effort level $e$ and $M$ chooses the level of knowledge capital to use (this level is determined by the licensing contract under outsourcing). Finally, the gross surplus $U_{1}\left(K, s_{1}\right)$ is realized and payments are made.

At the beginning of $t=2, M$ offers $A$ a second employment contract involving a payment $w_{2}$ under FDI. If $A$ accepts, $M$ again chooses a level of knowledge capital utilization for $A$. Surplus $U_{2}\left(K, s_{2}\right)+V(e \mid K)$ is realized. The employment contract in both $t=1$ and $t=2$ can also specify the uses to which $A$ can put $M$ 's physical capital. Under outsourcing, $M$ and $A$ negotiate a second contract involving a transfer to $A$ of intellectual capital, $s_{2}$, and a licensing payment from $A$ to $M$ of $l_{2}$. If the contract is agreed to, $M$ transfers intellectual capital $s_{2}$ to $A$, and surplus $U_{2}\left(K, s_{2}\right)+V(e \mid K)$ is realized. Transfers at $t=2$ are determined via the Nash bargaining solution.

In all cases, the equilibrium levels of $e, s_{1}, s_{2}$ are the result of Subgame Perfect Nash equilibrium strategy choices by $A$ and $M$; and $U_{i}$ is sufficiently large relative to $K$ and $W$ so that in equilibrium it is profitable for $M$ to choose either FDI or outsourcing.

\section{ANALYSIS}

We begin by analyzing the complete contracting case where contracting on $e$ and $s_{i} \in[0, S]$ are feasible, so as to provide a benchmark for the subsequent analysis of the incomplete contracting situation. For the incomplete contracting case, we analyze first the FDI contract equilibrium and then the outsourcing equilibrium. Finally, we compare equilibrium payoffs for $M$ and determine the situations in which $M$ prefers 
FDI to outsourcing.

\subsection{The complete contracting case}

The complete contracting solution is given as the solution to the problem

$$
\max _{e, s_{1}, s_{2}} U_{1}\left(K, s_{1}\right)+U_{2}\left(K, s_{2}\right)+V(e \mid K)-e
$$

Since both $U_{1}\left(K, s_{1}\right)$ and $U_{2}\left(K, s_{2}\right)$ are increasing in $s$ and $M$ can control the use of $S$ with complete contracting, $M$ chooses $s_{1}=s_{2}=S$. The level of effort for $A$ is given by $e^{*}$, defined by the condition

$$
V_{e}\left(e^{*} \mid K\right)=1
$$

\subsection{Equilibrium under FDI}

We begin by analyzing the equilibrium contract at $t=2$. Since $M$ owns the physical asset under FDI, $M$ can control the use of $K$ at $t=2$. Thus, $M$ can prevent $A$ from using $S$ for purposes other than $M^{\prime} s$ project in $t=2$. Consequently, $A$ 's outside option is simply $W$, and, since $U_{2}\left(K, s_{2}\right)$ is increasing in $s_{2}, M$ chooses knowledge capital

transfer of $s_{2}^{F}=S$. As a result, the contract that $M$ offers $A$ involves a payment $w_{2}^{F}=W . M$ 's payoff at $t=2$ is, therefore,

$$
\pi_{M 2}^{F}=U_{2}(K, S)+V(e \mid K)-W
$$

At $t=1, M$ will optimally choose $s_{1}^{F}=S$, since $U_{1}\left(K, s_{1}\right)$ is increasing in $s_{1}$ and the payoff at $t=2$ is independent of the value of $s_{1}$. Further, since effort is costly 
for $A$ and $A$ 's compensation at $t=2$ is independent of $e, A$ will choose $e^{F}=0$. $M$, recognizing this fact, offers a payment of $w_{1}^{F}=W . M$ 's two period payoff from choosing FDI is thus

$$
\Pi_{M}^{F}=U_{1}(K, S)+U_{2}(K, S)+V(0 \mid K)-2 W-r K
$$

We summarize this discussion below:

Lemma 1 Under the FDI option, the unique equilibrium contract pair involves: i) transfers of knowledge capital of $s_{1}^{F}=s_{2}^{F}=S$, and ii) wage payments to $A$ of $w_{1}^{F}=$ $w_{2}^{F}=W$. Under this contract, $A$ chooses effort level $e^{F}=0$ and $M$ 's equilibrium payoff is $\Pi_{M}^{F}$ given in equation (3).

Note that, under FDI, the equilibrium contract is a standard wage-employment contract. The contract allows $M$, via control of physical capital, to control the use of $M$ 's knowledge capital. ${ }^{8}$ The agent employee exerts no (extra) effort in improving (maintaining) physical capital and undertakes no tasks other than those involved in working directly for $M$. The inefficient choice of $e$ by $A$ obtains because $M$ cannot commit to compensating $A$ for its investment in $e$. As such, the contract exhibits the oft discussed features of an insourced activity: low-powered incentives (and so problems of lower effort) but control over asset use.

\subsection{Equilibrium under outsourcing}

Unlike the case of FDI, under outsourcing $A$ now owns the physical capital while $M$ still owns the knowledge capital. This ownership difference impacts both the ability

\footnotetext{
${ }^{8} M$ will also require $A$ to use $K$ only for $M^{\prime} s$ project. Otherwise, $A$ may use $K$ for its own alternative purpose, given that he receives a fixed wage payment.
} 
of $M$ to control the use of knowledge capital and the incentives that $A$ has to invest in improving (maintaining) physical capital. To see the overall effect of this ownership difference, first consider the equilibrium contract at $t=2$. Since $A$ owns the physical capital, $A$ can control the use of $K$ and so can credibly threaten to use $K$ for own purposes. Indeed, $A$ will choose this option unless the contract at $t=2$ provides $A$ with sufficient inducement not to do so. Thus, the Nash bargaining solution at $t=2$ must account for $A$ 's alternative uses of $K$ - these uses form $A$ 's threat point in the bargaining - and compensate $A$ appropriately.

To see how the bargaining solution is obtained, note first that, if $M$ and $A$ fail to reach an agreement at $t=2$ and $s_{1} \geq \sigma S$, then $A$ can use the intellectual capital not controlled by $M$ under the initial licensing agreement and $A$ 's own physical capital for other uses. Specifically, $A$ can use $K$ and $s_{1}-\sigma S$ to generate return $U_{2}\left(K, s_{1}-\sigma S\right)+$ $V(e \mid K)$, through either producing an imitation of $M$ 's product, or putting the assets for some alternative purpose, or both. Of course, $A$ can also choose not to produce and obtain its option value $W$. Thus $A^{\prime} s$ disagreement payoff at $t=2$ is

$$
\max \left\{U_{2}\left(K, s_{1}-\sigma S\right)+V(e \mid K), W\right\},
$$

whereas $M$ earns zero in $t=2$ if no agreement is reached. From part (iii) of Assumption 1 , we have

$$
U_{2}\left(K, s_{1}-\sigma S\right)+V(e \mid K) \geq U_{2}(K, 0)+V(0 \mid K)>W .
$$

On the other hand, the maximum joint surplus for $M$ and $A$ if they reach agreement is $U_{2}(K, S)+V(e \mid K)$. 
Therefore, at $t=2$, according to the Nash bargaining solution, which splits the surplus equally between the two parties, $M^{\prime} s$ and $A^{\prime} s$ payoffs are, respectively:

$$
\begin{aligned}
\pi_{M 2}^{O} & =\frac{U_{2}(K, S)+V(e \mid K)-U_{2}\left(K, s_{1}-\sigma S\right)+V(e \mid K)}{2} \\
\pi_{A 2}^{O} & =\frac{U_{2}(K, S)+V(e \mid K)+U_{2}\left(K, s_{1}-\sigma S\right)+V(e \mid K)}{2}
\end{aligned}
$$

Anticipating this, during $t=1$ agent $A$ will choose $e$ to maximize

$$
\pi_{A 2}^{O}-e=\frac{U_{2}(K, S)+U_{2}(K, 0)}{2}+V(e \mid K)-e
$$

and the equilibrium $e$ under outsourcing is $e^{O}=e^{*}$, the efficient $e$ as defined in equation (2).

Turning next to the $t=1$ contract, since there is a perfectly elastic supply of agents at $t=1$ and knowledge capital is fully contractible for $s_{1} \leq \sigma S, M$ captures all incremental returns to the use of knowledge capital for $s_{1} \leq \sigma S$ : for $s_{1} \leq \sigma S, M$ 's licensing revenues at $t=1$ are $U_{1}\left(K, s_{1}\right)-(1-\gamma)(r K+W)$ (recall that $A$ can only borrow enough against future income to cover a fraction $\gamma$ of first-period costs. The rest must be covered out of first-period revenues). Since $U_{1}(\cdot)$ is increasing in $s_{1}, M$ will choose to license at least $\sigma S$ units of knowledge capital. Since $M$ cannot commit to transferring any $s_{1}>\sigma S\left(s_{1}>\sigma S\right.$ is not contractible) nor capture returns at $t=1$ from doing so, and since $M$ 's return at $t=2\left(\pi_{M 2}^{O}\right)$ is decreasing for $s_{1}>\sigma S$, the equilibrium licensing contract at $t=1$ has $s_{1}^{O}=\sigma S$. The licensing payment by $A$ to $M$ is

$$
l_{1}^{O}=U_{1}(K, \sigma S)-(1-\gamma)(r K+W)
$$


From (5) and (6), and recalling that in $t=1$ agent $A$ receives $U_{1}(K, \sigma S)$ but has capital cost $r K$ and effort cost $e^{*}$, we conclude that, under the equilibrium pair of outsourcing contracts, $A$ 's payoff is

$$
\begin{aligned}
\Pi_{A}^{O}= & \left.\pi_{A 2}^{O}\right|_{e=e^{*}}-e^{*}+U_{1}(K, \sigma S)-r K-l_{1}^{O} \\
= & \frac{U_{2}(K, S)+U_{2}(K, 0)}{2}+V\left(e^{*} \mid K\right)-e^{*}+U_{1}(K, \sigma S)-r K \\
& -\left[U_{1}(K, \sigma S)-(1-\gamma)(r K+W)\right] \\
= & \frac{U_{2}(K, S)+U_{2}(K, 0)}{2}+V\left(e^{*} \mid K\right)-e^{*}-r K+(1-\gamma)(r K+W) .
\end{aligned}
$$

Since $A$ has an opportunity cost of $2 W$ to work with $M$ under the licensing contract, in equilibrium it is required that $\Pi_{A}^{O} \geq 2 W$, which we assume to hold.

$M^{\prime} s$ equilibrium payoff from outsourcing is, from (4) and (6):

$$
\Pi_{M}^{O}=\frac{U_{2}(K, S)-U_{2}(K, 0)}{2}+U_{1}(K, \sigma S)-(1-\gamma)(r K+W)
$$

The results for the outsourcing contract are summarized below.

Lemma 2 Under the outsourcing option, the unique equilibrium contract pair is

$$
\begin{aligned}
& l_{1}^{O}=U_{1}(K, \sigma S)-[(1-\gamma)(r K+W)], s_{1}^{O}=\sigma S \\
& l_{2}^{O}=\frac{U_{2}(K, S)-U_{2}(K, 0)}{2}, s_{2}^{O}=S .
\end{aligned}
$$

The equilibrium effort choice by $A$ is $e^{*}$. Equilibrium payoffs for $A$ and $M$ are $\Pi_{A}^{O}$ and $\Pi_{M}^{O}$ given in equations (7) and (8).

Note that outsourcing generates efficient effort by the agent but leads to inefficient 
transfer of intellectual capital. Also, because of $A$ 's limited access to capital markets, $M$ implicitly covers some fraction of the physical capital costs. FDI, by contrast, leads to efficient transfer of knowledge capital but shirking by the agent. Also, $M$ bears the full cost of physical capital. Below we investigate the circumstances under which one option is preferred to the other.

\subsection{Equilibrium Choice of Organization Form}

To determine $M$ 's choice between FDI and outsourcing, one need only examine the payoff difference under the two options. From (3) and (8), this difference is given by

$$
\begin{aligned}
\Pi_{M}^{F}-\Pi_{M}^{O}= & {\left[U_{1}(K, S)+U_{2}(K, S)+V(0 \mid K)-2 W-r K\right] } \\
& -\left[\frac{U_{2}(K, S)-U_{2}(K, 0)}{2}+U_{1}(K, \sigma S)-(1-\gamma)(r K+W)\right] \\
= & {\left[U_{1}(K, S)-U_{1}(K, \sigma S)\right]+\left[\frac{U_{2}(K, S)+U_{2}(K, 0)}{2}+V\left(e^{*} \mid K\right)-W\right] } \\
& -\left[V\left(e^{*} \mid K\right)-V(0 \mid K)\right]-\gamma(w+r K)
\end{aligned}
$$

In (9), the term $U_{1}(K, S)-U_{1}(K, \sigma S)>0$ represents the gain from FDI due to better knowledge capital transfer. The term

$$
\frac{U_{2}(K, S)+U_{2}(K, 0)}{2}+V\left(e^{*} \mid K\right)-W>U_{2}(K, 0)+V(\tilde{e} \mid K)-W>0
$$

represents the increased surplus accruing to $M$ due to avoidance of hold-up under FDI created by the fact that $M$ owns the $K$ under FDI. ${ }^{9}$ The third term, $-\left[V\left(e^{*} \mid K\right)-V(0 \mid K)\right]$, represents the loss to $M$ due to the lower effort under FDI.

\footnotetext{
${ }^{9}$ That is, under FDI, $M$ only needs to pay $A$ an amount equal to $W$ in $t=2$, whereas under outsourcing $A$ will obtain $\frac{U_{2}(K, S)+U_{2}(K, 0)}{2}+V\left(e^{*} \mid K\right)$ in $t=2$ due to its ownership of $K$ and can hold up $M$ in demanding a higher payoff.
} 
The final term, $-\gamma(w+r K)$, reflects the ability of $M$ to recapture some of $A$ 's second-period hold-up rents under outsourcing by requiring $A$ to finance a portion of $(W+r K)$ in the first period: the higher $\gamma$, the large this effect which makes outsourcing more attractive (FDI less attractive). When $\Pi_{M}^{F}-\Pi_{M}^{O}>0, M$ chooses FDI; when $\Pi_{M}^{F}-\Pi_{M}^{O}<0, M$ chooses outsourcing.

Notice that for any given $S$, a lower $K$, or a lower $\frac{K}{S}$, indicates an industry that is more knowledge-capital intensive; whereas a higher $K$, or a higher $\frac{K}{S}$, indicates an industry that is more physical-capital intensive. It is simple to show that FDI will be chosen by an industry that has a sufficiently low physical capital intensity (K) for a given S. However, some addition structure is need to establish that outsourcing is chosen by an industry that has a relatively high physical capital intensity for a given S. We now state out main results in the next two propositions.

Proposition 1 Given any fixed $S$ : (i) There exists some $K_{1}>0$ such that when $K<K_{1}, \Pi_{M}^{F}-\Pi_{M}^{O}>0$. That is, $M$ will choose FDI when the production (industry) is sufficiently knowledge-capital intensive. (ii) Suppose that, for $s_{i} \in[0, S]$, both $\frac{\partial U_{i}\left(K, s_{i}\right)}{\partial K}$ and $\frac{d\left[U_{1}(K, S)-U_{1}(K, \sigma S)\right]}{d K}$ decrease in $K$ and $\frac{\partial U_{i}(K, S)}{\partial K} \rightarrow 0$ as $K \rightarrow \infty$. Then, there exists some $K_{2} \geq K_{1}>0$ such that when $K>K_{2}, \Pi_{M}^{F}-\Pi_{M}^{O}<0$. That is, $M$ will choose outsourcing when the production (industry) is sufficiently physical-capital intensive.

Proof. (i) We can rewrite $\Pi_{M}^{F}-\Pi_{M}^{O}$ as

$$
\begin{aligned}
& \Pi_{M}^{F}-\Pi_{M}^{O} \\
= & U_{1}(K, S)-U_{1}(K, \sigma S)+\frac{U_{2}(K, S)-U_{2}(K, 0)}{2}+ \\
& U_{2}(K, 0)+V(0 \mid K)-W(1+\gamma)-\gamma r K .
\end{aligned}
$$


Since $U_{i}\left(K, s_{i}\right)$ increase in $s_{i}$, we have $U_{1}(K, S)-U_{1}(K, \sigma S)>0$, and $U_{2}(K, S)-$ $U_{2}(K, 0)>0$. From (iii) of Assumption $1, U_{2}(K, 0)+V(0 \mid K) \geq(1+\gamma) W$. Therefore, when $K(>0)$ is sufficiently small, we must have $\Pi_{M}^{F}-\Pi_{M}^{O}>0$.

(ii) Since $\frac{\partial U_{i}\left(K, s_{i}\right)}{\partial K}$ and $\frac{\partial\left[U_{1}(K, S)-U_{1}(K, \sigma S)\right]}{\partial K}$ decrease in $K$,

$$
\begin{aligned}
& \frac{\partial\left[U_{1}(K, S)-U_{1}(K, \sigma S)+\frac{U_{2}(K, S)+U_{2}(K, 0)}{2}-\gamma(W+r K)\right]}{\partial K} \\
= & \frac{\partial\left[U_{1}(K, S)-U_{1}(K, \sigma S)\right]}{\partial K}+\frac{1}{2}\left[\frac{\partial U_{1}(K, S)}{\partial K}+\frac{\partial U_{1}(K, 0)}{\partial K}\right]-\gamma r
\end{aligned}
$$

is decreasing and is negative when $K$ is sufficiently large, due to $\frac{\partial U_{i}(K, S)}{\partial K} \rightarrow 0$ as $K \rightarrow \infty$. Thus $U_{1}(K, S)-U_{1}(K, \sigma S)+\frac{U_{2}(K, S)+U_{2}(K, 0)}{2}-\gamma(W+r K)$ is a (strictly) concave function that decreases when $K>K^{\prime}$ for some large enough $K^{\prime}$. Therefore, since $V(0 \mid K)-W \leq 0$ by (iv) of Assumption 1, there must exist some $K_{2} \geq K_{1}$ such that $\Pi_{M}^{F}-\Pi_{M}^{O}<0$ when $K>K_{2}$ (or when $\frac{K}{S}$ is sufficiently large).

Therefore, $M$ tends to choose FDI in knowledge-capital intensive industries. Since physical capital is relatively less important in an knowledge-capital intensive industry, the gain from FDI due to better knowledge capital transfer is more important than the loss due to lower effort by the agent and the saving of spending on the physical capital. The opposite is true for physical-capital intensive industries, where $M$ tends to choose outsourcing. Notice that for result (ii) in Proposition 1 to hold, we need the additional assumption that the marginal return of $K$ is decreasing and becomes arbitrarily small when $K$ is sufficiently large, as well as the marginal return of $K$ for the difference $U_{1}(K, S)-U_{1}(K, \sigma S)$ is also decreasing. ${ }^{10}$ This guarantees that the gain from better knowledge transfer under FDI will be outweighed by the losses due

\footnotetext{
${ }^{10}$ For example, if the profitability of an industry with requirements $(K, S)$ is given by $U_{i}(K, S)=$ $K^{\alpha} S^{1-\alpha}$, this additional assumption is satisfied.
} 
to poor incentive for effort and the increased spending on physical capital.

We can also say something about how $\Pi_{M}^{F}-\Pi_{M}^{O}$ changes when other parameters of the model change, for any fixed $K$ (and $S$ ). Notice that since a higher $S$ will make $S-\sigma S$ larger, it is unlikely that $U_{1}(K, S)-U_{1}(K, \sigma S)$ is lower with a higher $S$. Thus, if we assume that $U_{1}(K, S)-U_{1}(K, \sigma S)$ is non-decreasing in $S,{ }^{11}$ and notice that $U_{2}(K, S)$ is higher with higher $S$ from part (i) in Assumption 1, we will have $\Pi_{M}^{F}-\Pi_{M}^{O}$ higher with a higher $S$ from equation (10). Next, again from equation (10), a higher $\sigma$ lowers $U_{1}(K, S)-U_{1}(K, \sigma S)$, and thereby lowers $\Pi_{M}^{F}-\Pi_{M}^{O}$. We have thus established the following:

Proposition 2 (i) Given any fixed $K$, suppose that $U_{1}(K, S)-U_{1}(K, \sigma S)$ is nondecreasing in $S$. Then $\Pi_{M}^{F}-\Pi_{M}^{O}$ is higher with higher $S$ (or with higher $\frac{S}{K}$ ); that is, the relative incentive for FDI is higher in a more knowledge-capital intensive industry. (ii) For any fixed $K$ and $S, \Pi_{M}^{F}-\Pi_{M}^{O}$ is lower with higher $\sigma$; that is, the relative incentive for outsourcing is higher if a higher portion of knowledge capital is contractible at $t=1$.

For a fixed $K$, a higher $S$ (or higher $\frac{S}{K}$ ) increases the relative incentive for FDI for the similar reason given after Proposition 1: a more knowledge-capital intensive industry benefits more from better knowledge capital transfer relative to other considerations. On the other hand, if a higher portion of knowledge capital is contractible, there will be less a problem of knowledge capital transfer under outsourcing, which increases the incentive for outsourcing, all else being equal.

To illustrate our findings, consider the following three examples.

\footnotetext{
${ }^{11}$ This additional assumption is again satisfied if $U_{i}(K, S)=K^{\alpha} S^{1-\alpha}$.
} 
Example 1 Suppose that $U_{i}(K, S)=K^{\alpha}(1+S)^{1-\alpha}$, and $V(e \mid K)=-\frac{1}{5} r K(1-40 e)^{2}$. Then, part (i) and (ii) of Assumption 1 are always satisfied; part (iii) and (iv) are satisfied as long as $K^{\alpha}-\frac{1}{5} r K>W$. Furthermore, both the additional assumption used in part (ii) of Proposition 1 and the additional assumption used in part (i) of Proposition 2 are satisfied. We have:

$$
\begin{aligned}
& \Pi_{M}^{F}-\Pi_{M}^{O} \\
= & U_{1}(K, S)-U_{1}(K, \sigma S)+\frac{U_{2}(K, S)+U_{2}(K, 0)}{2}+V(0 \mid K)-W-\gamma(W+r K) \\
= & K^{\alpha}(1+S)^{1-\alpha}-K^{\alpha}(1+\sigma S)^{1-\alpha}+\frac{K^{\alpha}(1+S)^{1-\alpha}+K^{\alpha}}{2}-\frac{1}{5} r K-W-\gamma(W+r K) \\
= & K^{\alpha}\left[\frac{3}{2}(1+S)^{1-\alpha}-(1+\sigma S)^{1-\alpha}+\frac{1}{2}\right]-\left(\frac{1}{5}+\gamma\right) r K-(1+\gamma) W .
\end{aligned}
$$

Suppose in addition that $\gamma=\frac{2}{3}, r=0.5, \alpha=0.5, W=0.5, \sigma=0.3, S=1$, and $K \in[0.94,7.02]$. Then, it is stragightforward to verify that $K^{\alpha}-\frac{1}{5} r K>W, \Pi_{M}^{F}>0$, $\Pi_{M}^{O}>0$, and $\Pi_{A}^{O}>2 W$. Hence all the assumptions of our model are satisfied, and

$$
\begin{aligned}
\Pi_{M}^{F}-\Pi_{M}^{O} & =K^{0.5}\left[\frac{3}{2}(1+1)^{0.5}-(1+0.5)^{0.5}+\frac{1}{2}\right]-\left(\frac{1}{5}+\frac{2}{3}\right) 0.5 K-\left(1+\frac{2}{3}\right) 0.5 \\
& \gtreqless 0 \text { if } K \lesseqgtr 5.9155 .
\end{aligned}
$$

That is, corresponding to Proposition $1, K_{1}=K_{2}=5.9155$.

Example 1 illustrates our findings in Propositions 1: for a given fixed $S, M$ chooses FDI when $K$ (or $\frac{K}{S}$ ) is below some critical value, and chooses outsourcing when $K$ ( or $\frac{K}{S}$ ) is above some critical value. Notice that in this example the critical values are the same, i.e., $K_{1}=K_{2}$. In this example, as well as in the following two examples, the condition that $\Pi_{A}^{O}>2 W$ imposes the binding constraints on how high and how 
low the parameter value $K$ is allowed for the model.

Example 2 Suppose that everything is the same as in Example 1 above except that now $\sigma=0.7$, then again all assumptions are satisfied, and

$$
\begin{aligned}
\Pi_{M}^{F}-\Pi_{M}^{O} & =K^{0.5}\left[\frac{3}{2}(1+1)^{0.5}-(1+0.7)^{0.5}+\frac{1}{2}\right]-\left(\frac{1}{5}+\frac{2}{3}\right) 0.5 K-\left(1+\frac{2}{3}\right) 0.5 \\
& \geqq 0 \text { if } K \lesseqgtr 4.5922 .
\end{aligned}
$$

Thus, with a higher $\sigma, \Pi_{M}^{F}-\Pi_{M}^{O}$ is lower for any given $K$, and $K_{1}=K_{2}=4.5922$.

Example 2 illustrates Part (ii) of Proposition 2: With a higher $\sigma$, the incentive for FDI becomes lower relative to that for outsourcing. This is reflected by the smaller set of $K$ for which $\Pi_{M}^{F}>\Pi_{M}^{O}$ as $\sigma$ increases from 0.5 to 0.7 , as compared to Example 1.

Example 3 Suppose again that everything is the same as in Example 1 above, except that now $S=2$ and $K \in[0.94,11.045]$. Then again all assumptions are satisfied, including

$$
\Pi_{A}^{O}-2 W>0 \text { if } K \in[0.6,11.04] .
$$

We have:

$$
\begin{aligned}
\Pi_{M}^{F}-\Pi_{M}^{O} & =K^{0.5}\left[\frac{3}{2}(1+2)^{0.5}-(1+1)^{0.5}+\frac{1}{2}\right]-\left(\frac{1}{5}+\frac{2}{3}\right) 0.5 K-\left(1+\frac{2}{3}\right) 0.5 \\
& \gtreqless 0 \text { if } K \lesseqgtr 10.915 .
\end{aligned}
$$

Thus, with a higher $S, \Pi_{M}^{F}-\Pi_{M}^{O}$ is higher for any given $K$, and $K_{1}=K_{2}=10.915$. 
Example 3 illustrates Part (i) of Proposition 2: With a higher $S$, the incentive for FDI becomes higher relative to that for outsourcing. This is reflected by the larger set of $K$ for which $\Pi_{M}^{F}>\Pi_{M}^{O}$ as $S$ increases from 1 to 2, as compared to Example 1.

Together, our results imply that FDI is the preferred choice for $M$ when $M$ 's product is intensive in knowledge capital and knowledge capital is difficult for $M$ to control under a licensing agreement. When $M$ 's activity is either extremely intensive in physical capital or knowledge capital is easy to protect under a licensing agreement, outsourcing is $M$ 's preferred choice. Thus, for instance, we see the manufacturing of standard electronics equipment such as DVD players, CD players and regular TV's outsourced as are items like Nike or Adidas athletic shoes. In all of these cases, production is physical capital intensive and, what knowledge capital there is, is easily controlled under a licensing agreement. But we do not see Microsoft outsourcing the writing of its operating systems.

Our theoretical findings have potentially testable implications. In particular, both Propositions 1 and 2 suggest that firms produce products that are more knowledgecapital intensive and/or have a lower $\sigma$ tend to choose FDI. Such a firm will have a higher return at $t=1\left(U_{1}(K, S)>U(K, \sigma S)\right)$, and a lower replacement value (physical capital value plus the value of explicit intellectual capital). Consequently, such a firm will have a higher Tobin's $q .{ }^{12}$ This suggests a relationship between Tobin's $q$ and outsourcing - firm's with high Tobin's $q$ are more likely to be using FDI while firm's with low Tobin's $q$ are more likely to be outsourcing. This prediction is supported by some existing empirical evidence. Morck and Yeung (1991), for example, show

\footnotetext{
${ }^{12}$ Recall that Tobin's $q$ is defined as

$$
q=\frac{\text { market value of the firm }}{\text { replacement cost of firm assets }} .
$$
}


that controlling for explicit knowledge capital such as R\&D and advertising expenditures, firms with more owned foreign subsidiaries have a higher Tobin's $q$. Our theory provides directions for further empirical studies.

Our results also have implications for the choice of organizational mode over the product life cycle. Specifically, the product life cycle is often characterized in terms of recently innovated products being relatively intensive in intellectual assets and established products being relatively intensive in physical assets. Under this interpretation, a recently introduced product is one with $K / S$ small and so it's manufacturer is likely to choose FDI; an established product is one with $K / S$ large and so its manufacturer is likely to choose outsourcing. Again, we have some observations of this pattern in the data. Sharp, for instance, produces it's latest flat-panel and Plasma TV's for Europe in an owned facility in Eastern Europe. Its standard TV's and older flat-panel models are produced by outsourced manufacturers in Asia.

Markets in which technologies evolve rapidly so that knowledge capital quickly depreciates are ones that the model also predicts should feature more outsourcing. In this case, markets with rapid technological change will feature low values for $\frac{U_{2}(K, S)}{2}-$ $W$ as rents from knowledge capital decline quickly with time. As a result, the holdup problem that FDI solves is less severe in markets with rapid technological change. This makes outsourcing a more attractive option. Similarly, products that require highly skilled agents that are in scarce supply in the foreign country - products for which $W$ is large relative to $U_{2}(K, S)$ - are also more likely to be outsourced. Again, the reason is that the value that FDI generates in terms of reduced hold up is lower since the agent already captures a large share of second-period rents due to the high value of $W$. 
To the extent that stronger intellectual property protection or contract enforcement is likely to lead to a higher $\sigma$, Proposition 2 further suggets that outsourcing to a country is likely to increase as it implements stronger intellectual property protection.

Finally, note that the larger is $\gamma$, the larger is the amount of the second-period surplus earned by $A$ under outsourcing that $M$ can claim in the first period licensing contract and the larger is the share of physical capital costs borne by $A$. As a result, as $\gamma$ becomes larger, outsourcing becomes a more attractive option. Since low values of $\gamma$ are associated with greater capital market imperfections in the foreign country, FDI is more likely when capital market imperfections are significant whereas outsourcing is more likely when capital market imperfections are less significant.

\section{CONCLUSION}

In this paper we have examined how the non-excludability of knowledge capital leads to the ownership of a complementary asset, in our case physical capital, as a means of protecting intellectual property. The result we find is that firms that are largely dependent on knowledge capital for their returns will protect these returns by engaging in FDI rather than outsourcing. The ownership of physical capital protects the returns of the complementary asset, knowledge capital. The cost of this ownership is weak incentives for firm management. Firms whose returns rely little on knowledge capital and mainly on physical capital outsource to provide stronger management incentives.

We conclude the paper by summarizing six empirical implications of the model. Three relate to the firms and their technologies. (1) Firms that choose FDI will have larger values of Tobin's $q$, all else equal, than firms that outsource, (2) firms and 
products that are subject to product cycles are likely to use FDI early in a cycle and outsourcing later, and (3) firms in industries with rapidly developing technologies may be more likely to choose outsourcing. Three predictions relate to host-market characteristics. FDI is more likely chosen in markets where (4) skilled labor has a low opportunity cost, (5) intellectual property rights and contract enforcement are relatively weak, and (6) capital markets are relatively under-developed. 


\section{REFERENCES}

Antrás, Pol (2003), "Firms, Contracts, and Trade Structure", Quarterly Journal of Economics 118, 1375-1418.

Antrás, Pol (2005), "Incomplete Contracts and the Product Cycle", American Economic Review 95, 1054-1071.

Caves, Richard E.(2007), Multinational Enterprise and Economic Analysis. Cambridge: Cambridge University Press, third edition.

Davidson William H. and Donald G. McFetridge (1984), "International Technology Transactions and the Theory of the Firm", Journal of Industrial Economics 32, 253264.

Ethier, Wilfred J. and James R. Markusen (1996), "Multinational Firms, Technology Diffusion and Trade," Journal of International Economics 41, 1-28.

Feenstra, Robert C. and Gordon H. Hanson (2005), "Ownership and Control in Outsourcing to China: Estimating the Property-Rights Theory of the Firm", Quarterly Journal of Economics 120, 729-761.

Fosfuri, Andrea, Massimo Motta and Thomas Rønde (2001), Foreign direct investments and spillovers through workers' mobility, Journal of International Economics $53,205-222$.

Glass, Amy J. And Kamal Saggi (2002), "Multinational firms and technology transfer", Scandinavian Journal of Economics 104, 495-513.

Grossman, Sanford J. and Oliver D. Hart (1986), "The Costs and Benefits of Ownership: A Theory of Vertical and Lateral Integration, Journal of Political Economy 94, 691-719.

Grossman, Gene and Elhanan Helpman (2002), "Integration versus Outsourcing in Industry Equilibrium", Quarterly Journal of Economics 117, 85-120.

Grossman Gene M. And Elhanan Helpman (2004), "Managerial incentives and the international organization of production", Journal of International Economics 63, 237-262.

Hart, Oliver D. and John Moore (1990), "Property Rights and the Nature of the Firm", Journal of Political Economy 98, 1119-1158. 
Horstmann, Ignatius J. and James R. Markusen (1987), "Licensing Versus Direct Investment: A Model of Internalization by the Multinational Enterprise," Canadian Journal of Economics 20, 464481.

Mansfield, Edwin and Anthony Romeo (1980), "Technology Transfer to Overseas Subsidiaries by U.S. Firms", Quarterly Journal of Economics 94, 737-750.

Markusen, James R. (1995), "The Boundaries of Multinational Enterprises and the Theory of International Trade", Journal of Economic Perspectives 9, 169-189.

Markusen, James R. (2001), "Contracts, Intellectual Property Rights, and Multinational Investment in Developing Countries", Journal of International Economics 53, 189-204.

Markusen, James R. (2002), Multinational Firms and the Theory of International Trade, Cambridge: MIT Press.

Maskus, Keith E, Kamal Saggi and Thitima Puttitanun (2005), "Patent Rights and International Technology Transfer through Direct Investment and Licensing", in Keith E. Maskus and Jerome H. Reichman (editors), International Public Goods and Transfer of Technology under a Globalized Intellectual Property Regime, Cambridge: Cambridge University Press, 265-281.

Morck, Randall and Bernard Yeung (1991), "Why Investors Value Multinationality", Journal of Business 64, 165-187.

Morck, Randall and Bernard Yeung (1992), "Internalization: An Event Study", Journal of International Economics 33, 41-56.

Smith, Pamela (2001), Patent rights and bilateral exchange: a cross-country analysis of U.S. exports, FDI, and licensing, Journal of International Economics, forthcoming.

Teece, David (1986), The Multinational Corporation and the Resource Cost of International Technology Transfer, Cambridge: Ballinger.

Wilson, Robert W. (1977), "The Effect of Technological Environment and Product Rivalry on R\&D Effort and Licensing of Inventions", Review of Economics and Statistics 59, 171-78.

Yang, G. F. And Keith E. Maskus (2001), "Intellectual property rights and licensing: An econometric investigation", Weltwirtschaftsliches Archiv 137, 58-79. 